\title{
Effects of N-methyl-thiotetrazole cephalosporin on haemostasis in patients with reduced serum vitamin $\mathrm{K}_{1}$ concentrations
}

\author{
I J MACKIE, K WALSHE, H COHEN, P McCARTHY,* M SHEARER, \\ S D SCOTT,** S J KARRAN,** S J MACHIN
}

From the Department of Haematology, Middlesex Hospital, London, the *Department of Haematology, Guy's Hospital, London, and the ${ }^{* *}$ Department of Surgery, Southampton General Hospital

SUMMARY Two patients with low random serum vitamin $\mathrm{K}_{1}$ concentrations but with normal prothrombin times and normal biological assays of the vitamin $\mathrm{K}$ dependent coagulation proteins were treated with an $\mathrm{N}$-methyl-thiotetrazole cephalosporin (cefotetan) postoperatively. Four to six days later both patients developed a prolonged prothrombin time and a noticeable and specific lowering of the clotting activities of factors II, VII, IX and X, though the serum vitamin $\mathrm{K}_{1}$ concentrations remained unchanged. Crossed immunoelectrophoresis of prothrombin showed the appearance of a second peak corresponding to descarboxyprothrombin (PIVKA II). These abnormalities corrected after vitamin $\mathrm{K}$ administration. These data are consistent with the hypothesis that cephalosporins with an N-methyl-thiotetrazole side chain inhibit the hepatic utilisation of vitamin $K$ but that this only causes hypoprothrombinaemia when liver reserves of vitamin $\mathrm{K}$ are low.

Cephalosporin antibiotics have been known for some years to be associated with reduced synthesis of the vitamin $\mathrm{K}$ dependent clotting factors II, VII, IX and $\mathrm{X}$ and occasionally to be responsible for clinical bleeding episodes. ${ }^{1}$ Clinical reports have usually implicated cephalosporins with $\mathrm{N}$-methylthiotetrazole (NMTT) side chains such as latamoxef, ${ }^{23}$ cefamandole, ${ }^{4}$ and cefoperazone. ${ }^{5}$ These events occurred most in patients with renal failure, those who are severely malnourished with chronic gastrointestinal disease, or those who had been receiving prolonged parenteral nutrition. ${ }^{6}$ It has been suggested that NMTT cephalosporins may cause vitamin $\mathrm{K}$ deficiency by suppressing the vitamin $\mathrm{K}$ producing micro-organisms of the colonic microflora. ${ }^{78}$ Contradicting this hypothesis is the lack of evidence that menaquinones (vitamin $\mathrm{K}_{2}$ ) can be absorbed from the colon and the fact that other antibiotics such as tetracyclines, which also strongly suppress the bowel flora, are not known to be associated with vita$\min \mathrm{K}$ deficiency. Another hypothesis is that the NMTT side chain directly inhibits the vitamin $K$ dependent $\gamma$-carboxylation of clotting factors in the liver cell..$^{910}$

Cefotetan (ICI) is a new compound in the cephamycin subdivision of the cephalosporins with an Accepted for publication 21 May 1986
NMTT side chain. ${ }^{11}$ We investigated the effects of this new cephalosporin on vitamin $K_{1}$ metabolism and hepatic synthesis of the vitamin $K$ dependent coagulation factors after parenteral nutrition given over several days to two patients with a normal prothrombin time and normal factor II, VII, IX and X assays before treatment. Both patients, however, had subnormal serum vitamin $K_{1}$ concentrations before treatment was started.

\section{Patients}

\section{CASE 1}

An 81 year old woman presented with a two month history of generalised abdominal pain and vomiting over the previous week. On admission (day 1), a diagnosis of a strangulated left femoral hernia was made and operative repair was carried out that day. Prophylactic antibiotic cover was started with intravenous cefotetan $(2 \mathrm{~g})$ given every 12 hours; treatment was continued for four days. She gave a history of recent weight loss, but routine liver function and renal function tests were within normal limits. On day four, after six doses of cefotetan, treatment was stopped and $10 \mathrm{mg}$ of vitamin $\mathrm{K}_{1}$ was given intramuscularly later that day when the prothrombin time was found to be prolonged. 


\section{CASE 2}

A 74 year old man presented with a 24 hour history of generalised abdominal pain that later localised to the right iliac fossa. On admission (day 1), peritonitis was diagnosed, and at operation that day a perforated gangrenous appendix was removed. Prophylactic antibiotic cover was started preoperatively with intravenous cefotetan $(2 \mathrm{~g})$ given every 12 hours and continued as treatment because free pus was found at operation. Liver function and renal function tests were within normal limits on admission. On day 6 , after ten doses of cefotetan, treatment was stopped and $10 \mathrm{mg}$ of vitamin $\mathrm{K}_{1}$ was then given intramuscularly because he was noted to have a prolonged prothrombin time.

\section{Methods}

Blood was collected by clean venepuncture into plain glass tubes for serum, or $0 \cdot 106 \mathrm{M}$ trisodium citrate (9:1) for plasma.

Serum concentrations of Vitamin $\mathbf{K}_{1}$ were measured by high performance liquid chromatography with dual electrode electrochemical detection, as described previously, ${ }^{12}$ except that quantification was made by reference to an internal standard (menaquinone-6) added at the extraction stage. The interrun coefficient of variation for 37 replicate analyses of a plasma pool (mean concentration 1100 $\mathrm{pg} / \mathrm{ml}$ ) carried out over six months was $11 \cdot 5 \%$.

Prothrombin time was measured manually using the human brain Manchester comparative reagent. Factor V and IX coagulant assays were performed by one stage methods using congenitally deficient substrate plasma. ${ }^{13}$ One stage factor VII assay was carried out with an artificially depleted substrate plasma.
Factor X was assayed using Russell's viper venom and "Diagen" factor X deficient plasma (Diagnostic Reagents Ltd). Prothrombin was measured by a two stage clotting assay ${ }^{13}$ or by a chromogenic substrate assay using Ecarin (Pentapharm Ltd) and S2238 (Kabi Vitrum Ltd). ${ }^{14}$ Factors II and IX antigen values were measured by immunoelectrophoresis, ${ }^{15}$ using suitable antisera (Dako Ltd, Diagnostica Stago Ltd). All factor II, VII, IX and X assays were standardised against a commercial reference plasma (Immuno Ltd) with a normal range of 50-200 U/dl. Crossed immunoelectrophoresis of prothrombin was performed, ${ }^{16}$ using calcium lactate buffer to separate descarboxyprothrombin (PIVKA-II) from $\gamma$-carboxylated prothrombin.

\section{Results}

Tables 1 and 2 show the results of assays for plasma coagulation factors and serum vitamin $\mathrm{K}_{1}$. Before treatment with antibiotics both patients had normal prothrombin times (13.7 and 13.7 seconds, normal range 12-14 seconds) and normal activities in the biological assays for the vitamin $\mathrm{K}$ dependent clotting factors II, VII, IX and X, but serum concentration of vitamin $\mathrm{K}_{1}$ (54 and $78 \mathrm{pg} / \mathrm{ml}$ ) were substantially reduced compared with those in the range (170-680 $\mathrm{pg} / \mathrm{ml}$ ) in 45 normal fasting adults using the same electrochemical method. After four and six days of treatment with cefotetan the serum vitamin $K_{1}$ concentrations remained unchanged (52 and $73 \mathrm{pg} / \mathrm{ml}$ ), but both patients developed a severe hypoprothrombinaemia, evidenced both by an increased prothrombin time (34.7 and 20.5 seconds) and clotting assays that showed a specific lowering of the four vitamin $\mathrm{K}$ dependent factors. Hypo-

Table 1 Coagulation results (case 1) after six 12 hourly doses of cefotetan and then six and 24 hours after 10 mg vitamin $K_{1}$ given intramuscularly

\begin{tabular}{|c|c|c|c|c|c|c|c|c|c|c|}
\hline Day & $\underset{(p g / m l)}{\operatorname{Vitamin}} K_{1}$ & $\begin{array}{l}\text { Prothrombin } \\
\text { time (seconds) }\end{array}$ & $\begin{array}{l}V: C \\
(U / d l)\end{array}$ & $\begin{array}{l}V I I: C \\
(U / d l)\end{array}$ & $\begin{array}{l}I X: C \\
(U / d l)\end{array}$ & $\begin{array}{l}I X: A g \\
(U / d l)\end{array}$ & $\begin{array}{l}X: C \\
(U / d l)\end{array}$ & $\begin{array}{l}I I: G \\
(U / d l)\end{array}$ & $\begin{array}{l}I I A g \\
(U / d l)\end{array}$ & $\begin{array}{l}\text { Ecarin } I I \\
(U / d l)\end{array}$ \\
\hline $\begin{array}{c}1 \\
4 \\
+6 \text { hours } \\
+24 \text { hours }\end{array}$ & $\begin{array}{r}54 \\
52 \\
1700 \\
36000\end{array}$ & $\begin{array}{l}13 \cdot 7 \\
34 \cdot 7 \\
38 \cdot 2 \\
14 \cdot 4\end{array}$ & $\begin{array}{l}52 \\
47 \\
54 \\
90\end{array}$ & $\begin{array}{r}59 \\
3 \\
39 \\
68\end{array}$ & $\begin{array}{r}180 \\
2 \\
38 \\
160\end{array}$ & $\begin{array}{l}76 \\
46 \\
75 \\
51\end{array}$ & $\begin{array}{l}77 \\
36 \\
32 \\
32\end{array}$ & $\begin{array}{l}87 \\
30 \\
21 \\
33\end{array}$ & $\begin{array}{r}78 \\
59 \\
108 \\
99\end{array}$ & $\begin{array}{l}77 \\
72 \\
77 \\
72\end{array}$ \\
\hline
\end{tabular}

Table 2 Coagulation results (case 2) after ten 12 hourly doses of cefotetan and then 12 hours after 10 mg vitamin $K_{1}$ given intramuscularly

\begin{tabular}{|c|c|c|c|c|c|c|c|c|c|c|}
\hline Day & $\underset{(\mathrm{pg} / \mathrm{ml})}{\operatorname{Vitamin}} K_{1}$ & $\begin{array}{l}\text { Prothrombin } \\
\text { time (seconds) }\end{array}$ & $\begin{array}{l}V: C \\
(U / d l)\end{array}$ & $\begin{array}{l}V I I: C \\
(U / d l)\end{array}$ & $\begin{array}{l}I X: C \\
(U / d l)\end{array}$ & $\begin{array}{l}I X: A g \\
(U / d I)\end{array}$ & $\begin{array}{l}X: C \\
(U / d l)\end{array}$ & $\begin{array}{l}I I: C \\
(U / d l)\end{array}$ & $\underset{\text { (U/dI) }}{\boldsymbol{I I}}$ & $\begin{array}{l}\text { Ecarin II } \\
(U / d l)\end{array}$ \\
\hline $\begin{array}{l}1 \\
6 \\
+12 \text { hours }\end{array}$ & $\begin{array}{r}78 \\
73 \\
27900\end{array}$ & $\begin{array}{l}13 \cdot 7 \\
20 \cdot 5 \\
14 \cdot 2\end{array}$ & $\begin{array}{l}50 \\
72 \\
61\end{array}$ & $\begin{array}{l}65 \\
37 \\
47\end{array}$ & $\begin{array}{r}150 \\
38 \\
126\end{array}$ & $\begin{array}{l}88 \\
80 \\
90\end{array}$ & $\begin{array}{l}90 \\
18 \\
59\end{array}$ & $\begin{array}{l}50 \\
29 \\
26\end{array}$ & $\begin{array}{l}108 \\
135 \\
132\end{array}$ & $\begin{array}{l}63 \\
77 \\
70\end{array}$ \\
\hline
\end{tabular}




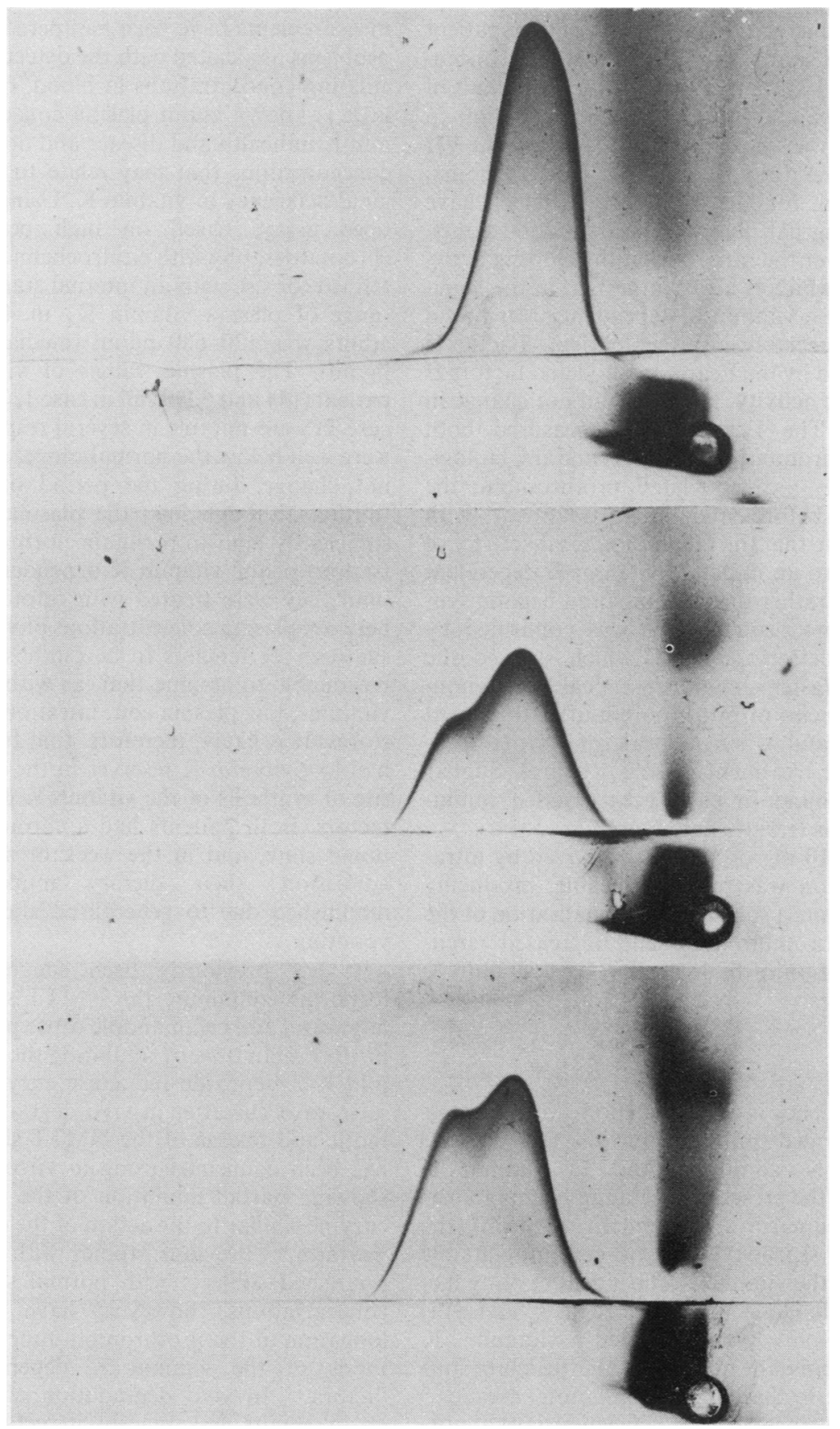


prothrombinaemia was most severe in the patient having the lower serum vitamin $K_{1}$, a serum concentration that was less than one third the lower limit of the normal range. In this patient the reduction in clotting factors was most noticeable for factors VII and IX (half lives four to six hours and 24 hours, respectively) than for factors $X$ and II, which have longer circulating half lives (48 hours and 60 hours, respectively). Over the same period the clotting activity of factor $\mathrm{V}$, which is also synthesised in the hepatocyte but is not a vitamin $\mathrm{K}$ dependent protein, did not change appreciably in either patient. Factor II activity measured by the Ecarin method and factors II and IX antigenic activity, however, did not change in either patient. The Ecarin assay measured both descarboxyprothrombin (PIVKA-II) and the biologically active fully $\gamma$-carboxylated prothrombin: the similar values before and after treatment with cefotetan indicate that the fall in biological activity of factor II is due to an impaired vitamin $\mathbf{K}$ dependent $\gamma$-carboxylation rather than an impaired hepatic synthesis of the core protein. This was confirmed by crossed immunoelectrophoresis, which showed the characteristic faster migrating peak of noncarboxylated species of prothrombin after treatment with cefotetan and a single peak of normal prothrombin before treatment (case 1) (figure). Similar findings were found in case 2 by crossed immunoelectrophoresis (results not shown).

The effect of $10 \mathrm{mg}$ of vitamin $\mathrm{K}_{1}$ given by intramuscular injection was most noticeable, producing after 12 to 24 hours a substantial normalisation of the prolonged prothrombin time and increased circulating concentration of biologically active vitamin $K$ dependent factors.

\section{Discussion}

Vitamin $\mathrm{K}$ deficiency is usually identified by the presence of a prolonged prothrombin time that corrects after vitamin $\mathbf{K}$ administration. In vitamin $\mathbf{K}$ deficiency, or in the presence of vitamin $\mathrm{K}$ antagonists (such as the coumarin anticoagulant warfarin), the postribosomal $\gamma$-carboxylation of certain glutamic acid residues of the vitamin $K$ dependent clotting factors (factors VII, IX, X and II, proteins C and S) is inhibited. ${ }^{17}$ Non $\gamma$-carboxylated vitamin $K$ dependent proteins are unable to bind calcium ions and are inactive in the blood coagulation cascade. ${ }^{18}$ Patients with severe vitamin $\mathrm{K}$ deficiency have abnormal inactive non $\gamma$-carboxylated proteins in their blood. These abnormal proteins have been called PIVKAs or descarboxyproteins.

A feature of the investigations in these two patients was the measurement of their plasma concentrations of vitamin $\mathrm{K}_{1}$ (phylloquinone). Until recently, such measurements have been hampered by the analytical problems associated with the detection of the low circulating concentrations in blood: consequently, very little is known about plasma concentrations of vita$\min \mathrm{K}$ in health and disease and nothing about those concentrations that may relate to an overt or marginal deficiency of vitamin $\mathbf{K}$. Using a recently developed assay, based on high performance liquid chromatography with electrochemical detection ${ }^{12}$ but refined for use with an internal standard, the normal range of plasma vitamin $K_{1}$ in 45 healthy fasting कै adults was $170-680 \mathrm{pg} / \mathrm{ml}$ (median 372, mean $412 \vec{\circ}$ $\mathrm{pg} / \mathrm{ml}$ ). The plasma values of vitamin $\mathrm{K}_{1}$ in the patients ( 54 and $52 \mathrm{pg} / \mathrm{ml}$ in case 1,78 and $73 \mathrm{pg} / \mathrm{ml}$ in case 2) were notable in several respects. Firstly, they were well below the normal range; secondly, they did not change during the period of the study and; $\omega$ thirdly, although low, the plasma vitamin $\mathrm{K}_{1}$ was $\overrightarrow{-}$ sufficiently high to maintain normal plasma concentrations of the vitamin $\mathrm{K}$ dependent clotting factors until they were treated with cefotetan. The relation between plasma concentrations of vitamin $K_{1}$ and tissue reserves remains to be established, but it seems reasonable to assume that, as with other fat soluble vitamins, low plasma concentrations reflect low body stores. It is likely, therefore, that both these patients had low vitamin $\mathrm{K}$ reserves in the liver, which is the site of synthesis of the vitamin $\mathrm{K}$ dependent clotting factors. Both patients had a chronically poor nutrog tional state, and in the week or so before hospital. admission, their dietary intake had furthep diminished due to generalised abdominal pain and vomiting.

It has previously been suggested that cephalosporins containing the NMTT side chain such as latamoxef and cefamandole cause prolongation of the prothrombin time by inhibiting the action of the vitamin K 2,3-epoxide reductase enzyme. ${ }^{19}$ This would seem to occur after in vivo degradation of the antibiotic and release of the NMTT side chain. ${ }^{910}$ This has been confirmed using in vitro rat liver systems showing partial inhibition of the epoxide reductase enzyme similar to the action of the oral anticoagulant warfarin. ${ }^{20}$ Previous studies with cefotetan in well nourished subjects with normal serum vitamin $\mathrm{K}_{1}$ concentrations, however, have shown no prolongation in the prothrombin time or decreased synthesis of the vitamin $\mathrm{K}$ dependent coagulation factors. $^{21}$ In vivo degradation of the NMTT side $N$ chain occurs less readily in cefotetan than other $N$ NMTT cephalosporins such as latamoxef. ${ }^{22}$ Thus only in clinical situations in which there is chronic $\omega$ vitamin $\mathrm{K}$ deficiency such as elderly patients with a poor dietary intake, patients receiving prolonged par- $\stackrel{\varrho}{C}$

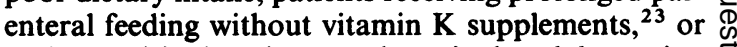
patients with chronic gastrointestinal malabsorption 
states $^{24}$ is cefotetan likely to inhibit the vitamin $\mathrm{K}$ oxidation reduction cycle and cause decreased $\gamma$-carboxylation of the $\mathrm{K}$ dependent proteins. Obviously in patients receiving warfarin and antibiotics with a cephalosporin containing the NMTT side chain, there is a risk of a synergistic reaction with a sudden decreased $\gamma$-carboxylation of the vitamin $\mathrm{K}$ dependent factors and excessive prolongation of the prothrombin time.

Although both these patients developed a prolonged prothrombin time, neither had any clinical bleeding episode or spontaneous bruising. Other NMTT containing cephalosporins, particularly latamoxef ${ }^{23}$ have often been associated with a clinical bleeding diathesis. These antibiotics, as well as inhibiting the vitamin $\mathrm{K}$ epoxide-reductase activity; also appreciably inhibit platelet function and prolong the bleeding time at standard therapeutic doses. ${ }^{25} \mathrm{Ce}$ fotetan does not inhibit platelet function or prolong the bleeding time ${ }^{21}$ and is thus much less likely to cause bleeding events.

We thank Dr R Bax (ICI, Alderley Edge, Cheshire) for helpful discussion and comments on this manuscript.

\section{References}

1 Andrassy K, Bechtold H, Ritz E. Hypoprothrombinaemia caused by cephalosporins. J Antimicrob Chemother 1985;15:133-6.

2 Weitekamp MR, Aber RC. Prolonged bleeding times and bleeding diathesis associated with moxalactam administration. JAMA 1983;249:69-71.

3 Morris DL, Fabricius PJ, Ambrose NS, Scammell B, Burdon DW, Keighley MRB. A high incidence of bleeding is observed in a trial to determine whether addition of metronidazole is needed with latamoxef for prophylaxis in colorectal surgery. $J$ Hosp Infect 1984;5:398-408.

4 Clancy CM, Glew RH. Hypoprothrombinaemia and bleeding associated with cephamandole. Lancet 1983;i:250.

5 Weitekamp MR, Caputo GM, Al-Mondhiry HAB, Aber RC. The effects of latamoxef, cefotaxime and cefoperazone on platelet function and coagulation in normal volunteers. $J$ Antimicrob Chemother 1985;16:95-101.

6 Smith CR, Lipsky JJ. Hypoprothrombinaemia and platelet dysfunction caused by cephalosporin and oxalactam antibiotics. $J$ Antimicrob Chemother 1983;11:496-9.

7 Bang NU, Tessler SS, Heidenreich RO, Marks CA, Mattler LE. Effects of oxalactam on blood coagulation and platelet function. Rev Infect Dis 1982;4 (supplement):5546-54.

8 Hochman R, Clark J, Rolla A, Thomas S, Kaldany A, D'Elia J. Bleeding in patients with infections. Arch Intern Med 1982;142:1440-2.
9 Lipsky JJ. N-Methyl-thiotetrazole inhibition of the gamma carboxylation of glutamic acid: possible mechanism for antibiotic associated hypoprothrombinaemia. Lancet 1983;i:192-3.

10 Lipsky JJ. Mechanism of the inhibition of the $\gamma$-carboxylation of glutamic acid by $\mathrm{N}$-methyl-thiotetrazole-containing antibiotics. Proc Natl Acad Sci 1984;81:2893-7.

11 Phillips I, King A, Shannon K, Warren C. Cefotetan: in-vitro antibacterial activity and susceptibility to B-lactamases. $J$ Antimicrob Chemother 1983;II (Suppl A):1-9.

12 Hart JP, Shearer MJ, McCarthy PT. Enhanced sensitivity for the determination of endogenous phylloquinone (vitamin $\mathbf{K}_{1}$ ) in plasma using high-performance liquid chromatography with dual-electrode electrochemical detection. Analyst 1985; 110:1181-4.

13 Thompson J. Blood coagulation and haemostasis. Edinburgh: Churchill Livingstone, 1980.

14 Bergstrom K, Egberg N. Determination of vitamin K sensitive coagulation factors in plasma. Studies of three methods using synthetic chromogenic substrates. Thromb Res 1978; 12:531-47.

15 Laurell CB. Quantitative estimation of proteins by electrophoresis in agarose gel containing antibodies. Anal Biochem 1966;15:45-68.

16 Laurell CB. Antigen-antibody crossed immunoelectrophoresis. Anal Biochem 1965;10:358-62.

17 Friedman PA. Vitamin K dependent proteins. New Engl J Med 1984;310:1458-60.

18 Friedman PA, Shia MA, Gallop PM, Griep AE. Vitamin Kdependent $\gamma$-carbon-hydrogen bond cleavage and nonmandatory concurrent carboxylation of peptide-bound glutamic acid residues. Proc Natl Acad Sci USA 1979;76:3126-9.

19 Bechtold H, Andrassy K, Jahnchen E, et al. Evidence for impaired hepatic vitamin $K_{1}$ metabolism in patients treated with N-methyl-thiotetrazole cephalosporins. Thromb Haemostas 1984;51 (3):358-61.

20 Uotila L, Suttie JW. Inhibition of vitamin K-dependent carboxylase in vitro by cefamandole and its structural analogues. $J$ Infect Dis 1983;148:571-8.

21 Machin SJ, Bowcock S, Mackie IJ, Ho D, Pozniak A. Haemostatic parameters: pilot study with cefotetan compared with other antibiotics. In: Lode H, Periti P, Strachan CJL, eds. Cefotetan, a long acting antibiotic. Edinburgh: Churchill Livingstone 1985:138-42.

22 Wise R, Dent J. Stability of B-lactam antibiotics containing Nmethylthiotetrazole side chain. Lancet 1983;ii:624-5.

23 Hands LJ, Royle GT, Kettlewell MGW. Vitamin K requirements in patients receiving total parenteral nutrition. $\mathrm{Br} J$ Surg 1985;72:665-7.

24 Krasinski SD, Russell RM, Furie BC, Kruger SF, Jacques PF, Furie $\mathbf{B}$. The prevalence of vitamin $\mathbf{K}$ deficiency in chronic gastrointestinal disorders. Am J Clin Nutr 1985;41:639-43.

25 Bowcock S, Mackie IJ, Ho D, Moulsdale M, Billings P, Machin SJ. Effects of various doses of Latamoxef on haemostasis. $J$ Hosp Infect (in press).

Requests for reprints to: Dr SJ Machin, Department of Haematology, Middlesex Hospital, Mortimer Street, London W1, England. 